\title{
Simulation Modelling In a Availability Thermal Power Plant
}

\author{
Sorabh Gupta ${ }^{l, *}$ and P.C. Tewari ${ }^{2}$ \\ ${ }^{1}$ Dpt of Mechanical Engineering, Haryana College of Technology and Management, Kaithal (Haryana), India \\ ${ }^{2}$ Mechanical Engineering, NIT, Kurukshetra (Haryana), India
}

Received 23 March 2010; Revised 7 June 2010; Accepted 14 March 2011

\begin{abstract}
The present paper deals with the opportunities for the availability simulation modelling and maintenance decision making in thermal power plant. These opportunities will be identified by evaluation of a simulation model to be built for the steam and water analysis system (SWAS) of a thermal power plant. This feasibility study covers two areas: development of an availability simulation model and decision making with the help of developed model. The present system of thermal plant under study consists of six subsystems with two possible states: working and failed. A probabilistic simulated model using Markov approach has been developed considering some assumptions. Availability decision matrix for each subsystem is also developed, which provide various availability levels. On the basis of this study, performance or availability of each subsystem of SWAS is analyzed and then maintenance priorities are decided for present system.
\end{abstract}

Keywords: Maintenance decision, Markov approach and Availability decision matrix.

\section{Symbols and Notations}

$\bigcirc$

Indicates the system is in operating state. Indicates the system is in failed state.

$\mathrm{S}_{\mathrm{i}}, \mathrm{i}=1-4$ : Represent full working states of Turbines, Boiler, Condenser and Heaters subsystem respectively.

E and F: Represent full working states of Condensation extraction pump and Feed pump subsystem respectively.

$\mathrm{E}_{1}, \mathrm{~F}_{1}$ : Denotes that the stand-by unit of the sub-system $\mathrm{E}$ and $\mathrm{F}$ are in working state.

${ }_{\mathrm{S}}, \mathrm{i}=1-4$ : Represent failed states of Turbines, Boiler, Condenser and Heaters subsystem respectively.

e and f: Represent failed states of Condensation extraction pump and Feed pump subsystem respectively.

$\mathrm{P}_{0}(\mathrm{t})$ : Probability of full capacity working without standby

\section{Introduction}

Reliability and maintenance engineering are very important for plant availability. The better the reliability and maintainability the better the availability of a plant is. Many authors on the technical possibilities of and achievements that can be made by availability simulation have performed extensive, theoretical research. Rotab and Kabir [27] states that the steady state or long term availability is the easiest to obtain and can be obtained by using the MTBF as a measure for reliability and the MTTR as a measure for maintainability. The often-used expression for mean availability is then obtained as: unit.

$P_{i}(t), i=5,6$ and 12: $\quad$ Probabilities of full capacity working with standby units.

$\mathrm{P}_{\mathrm{i}}(\mathrm{t}), \mathrm{i}=1-4,7-11$ and 13-23: Probabilities of the system in failed states.

$\phi_{i}, \mathrm{i}=1-6$ : Mfigean failure rates of $\mathrm{S}_{\mathrm{i}}(\mathrm{i}=1-4), \mathrm{E}$ and $\mathrm{F}$ subsystems respectively.

$\lambda_{i}, \mathrm{i}=1-6$ : Mean repair rates of $\mathrm{S}_{\mathrm{i}}(\mathrm{i}=1-4), \mathrm{E}$ and $\mathrm{F}$ subsystems respectively.

$\mathrm{P}_{\mathrm{i}}^{\prime}(\mathrm{t})$ : Represents the derivative w.r.t. time $(\mathrm{t})$.

Av. : Steady state availability of the system.

From this formula it can be concluded that increase of the reliability (MTBF) will increase the availability since the influence of maintainability will decrease. The larger time between failures will be in comparison with the repair time, the more the availability will approach one. This would mean the plant would always be available. At a highly aggregated level there can be three factors identified, they are plant design, operation and maintenance, which influence the availability. Lamb [26] describes the relation between availability, reliability and maintainability, with the help of fig. 1.

$$
A(\infty)=\frac{M T B F}{M T B F+M T T R}
$$




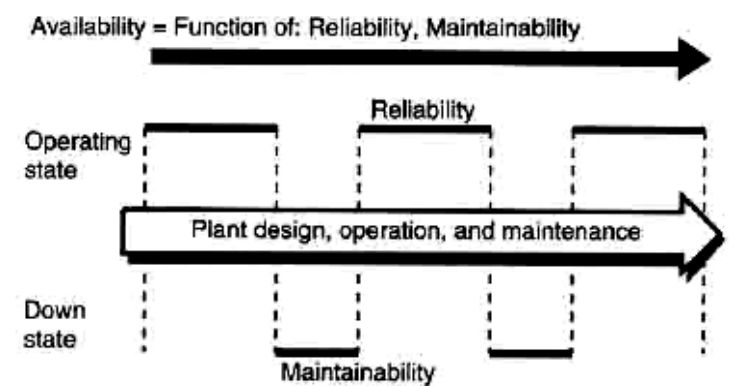

Fig 1. Relations between availability, reliability and maintainability

Van [15] state that the influence of certain pieces of equipment on reliability can be two folds. Either the equipment fails so often that there is loss of output due to often downtime, or the equipment fails only on exception but is of such complexity or criticality that it takes very long to replace or repair. The equipment that fails very frequently can be said to have very low reliability and the equipment that takes very long time to be replaced or repaired can be said to have very low maintainability. Both result in low availability and are thus considered critical in this study. Availability simulation modelling can provide insight in these cases by identifying exactly those pieces of equipment that are critical for availability. With a simulation model experiments can be made with different maintenance strategies and their influence on reliability and maintainability. Major deliverable of availability simulation modelling is that it quantifies the results of analysis and the analyses are based on real data, derived from the plant.

A thermal power plant is a complex engineering system comprising of various systems: Coal handling, Steam Generation, Cooling Water, Crushing, Ash handling, Power Generation, Feed water and most important Steam and water analysis system (SWAS). The optimization of each system in relation to one another is imperative to make the plant profitable and viable for operation. Effectiveness of thermal power plant is mainly influenced by the availability, reliability and maintainability of the plant, and its capability to perform as expected. Reliability analysis techniques have been gradually accepted as standard tools for the planning and operation of automatic and complex thermal power plants. Blischke and Murthy [43] suggested that since failure cannot be prevented entirely, it is important to minimize both its probability of occurrence and the impact of failures when they do occur. To maintain the designed reliability, availability and maintainability characteristics and to achieve expected performance, an effective maintenance program is a must and the effective maintenance is characterized by low maintenance cost.

The maintenance of repairable systems has been widely studied by many authors, considering different focus of interest, such as the repair/replacement policy, periodic inspections, degrading, optimization problems, among other topics. The behaviour of complex systems can be studied in terms of their reliability, availability and maintainability (RAM). For example, Kurien [17] developed a simulation model for analyzing the reliability and availability of an aircraft training facility. The model was useful for evaluating various maintenance alternatives. According to Ebling [9], factors that affect RAM of a repairable system include machinery operating conditions, maintenance and infrastructural facilities. Barabady and Kumar [14] conclude that from an economic point of view, high reliability is desirable to reduce the maintenance costs of systems. Reliability analysis has helped in identifying the critical and sensitive subsystems in the electricity production system, which has a major effect on system failure. Therefore, a focus on reliability is critical for the improvement of equipment performance and ensuring that equipment is available for production as per production schedules.

For the prediction of availability, several mathematical models have been discussed in literature, which handle wide degree of complexities [for example, Balaguruswamy [10] and Dhillon [6]. Most of these models are based on the Markovian approach, wherein the failure and the repair rates are assumed to be constant. In other words, the times to failure and the times to repair follow exponential distribution. During the past decade, a large number of analysis tools (for example, Johnson and Malek [5], Cirado et al. [11], Butler [29], Koren and Gaertner [16] and Sanders and obal [42]) for reliability, availability, performance and performability modelling were developed. These tools encompass different modelling paradigms such as fault trees, Markov chains, Petri nets and Activity nets. Advantages of Markov chains are the capability of modelling systems with shared repair. According to Malhotra and Trivedi [20], if the system structure is dynamic rather than static, this can be modeled accurately by Markov chains but only approximately by fault trees or reliability block diagrams. Some of the Markov analysis tools are; EHARP: suggested by Somani et al. [3 and 4], SHARPE: described by Sahner and Trivedi [25], SURE: given by Butler [24], SURF-2: suggested by Beounes et al. [8], HIMAP: by Krishnamurthy et al. [12] and TANGRAM: by Bernson et al. [30]. Lim and Chang [41] studied a repairable system modeled by a Markov chain with two repair modes. A text of general interest for studying reliability systems and performance measures is that of Hoyland and Rausand [2]. Other texts of interest related to the topics studied in the present paper are Avel and Jensen [40], Birolini [1], Gnedenko and Ushakov [7] and Ushakov [13].

\subsection{Architecture of the Paper}

The section 2 presents and discusses the processing and description of steam and water analysis system used for making the transition diagram. The assumptions used for development of simulation model are also listed in this section. Section 3 describes the development of simulation model, with brief introduction of Markov approach. Section 4 describes the performance evaluation for decision-making in this study. Section 5 and 6 describes the results and conclusions respectively.

\section{Steam And Water Analysis System (SWAS)}

Operating power plants efficiency is very important in the economics of power generation. This requires that all the systems function at their peak performance over long term operation. Steam and water analysis system helps power plants to function efficiently and keeps them in continuous operation for optimal performance. Sharma [22] states that in SWAS, the chemically treated water flowing through the water walls of the boiler furnace gets evaporated into steam by absorption of heat. The steam is further heated in the super-heaters. The dry, high-pressure high temperature steam is then fed to the steam turbine. There, the steam is 
expanded through the three cylinders and thermal energy of steam is converted into mechanical energy of the turbine shaft, which is utilized to a rotate generator and produce electric energy. The steam discharged from the H.P. turbine is returned to reheaters in the boiler. After it is reheated, the steam flows to I.P. turbine and finally it expands in L.P. turbine. After doing the useful work in the steam turbine, the exhaust steam flows into a condenser where it is condensed to water. From the condenser, the condensed steam (condensate) is pumped through condensate extraction pump (CEP) to deaerator, after its temperature is raised in H.P. feed water heater with the help of steam taken from H.P. turbine. From the deaerator, the feed pump forces the feed water under pressure to the economizer in the boiler, after the temperature of feed water is raised in H.P. feed water heater with the help of steam taken from H.P. turbine. In the economizer, the hot flue gases leaving the boiler further heat up the feed water. From the economizer, the feed water enters the boiler drum to which water tube walls and superheaters of boiler are connected, to generate super-heated steam. The functioning of SWAS can be easily understood with the help of fig. 2 .

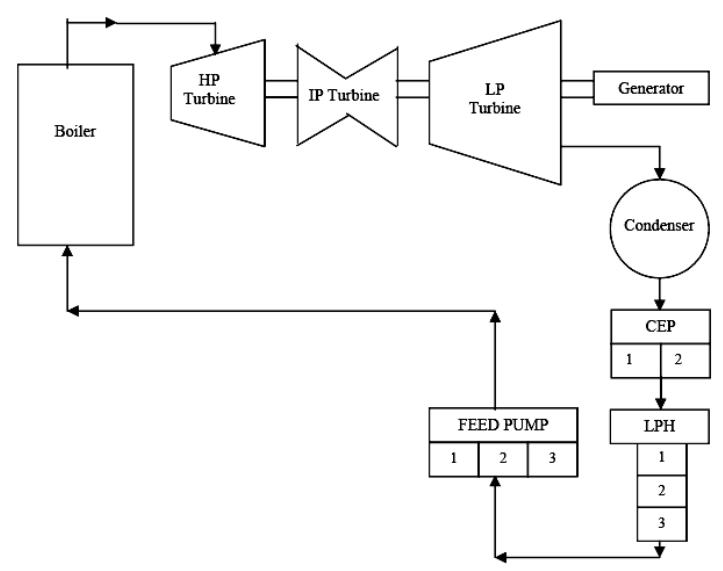

Fig. 2. Functioning of Steam and water analysis system (SWAS)

\subsection{System Configuration}

A typical system consists of a number of components or subsystems connected to each other logically either in series or in parallel in most cases. The performance of the system depends on its configuration and performance of its subsystems [31]. Before analyzing the failure data, it is better to describe the configuration of overall steam and water analysis system and classify it into various subsystems so that the failures can be categorized. For the simulation modelling, the SWAS consists of following six subsystems:

1. The 03 turbines in series denoted by $\mathrm{S}_{1}$, constituting one subsystem in which, failure of any subsystem one results in to system failure.

2. The boiler is used without any standby subsystem and denoted by $\mathrm{S}_{2}$, failure of which leads to system failure.

3. The only condenser as third subsystem and is denoted by $\mathrm{S}_{3}$, failure of which leads to system failure.

4. The heater subsystem is denoted by $\mathrm{S}_{4}$, consisting of three heaters in series .Failure of one reheater will lead to system failure.

5. E denotes the condensate extraction pump subsystem, which comprise of 02 pumps, at a time one is in operation, while other is kept as standby. The system failure takes place when both fail.

6. The feed pump subsystem is denoted by F, which consists of three pumps, two are to work during operation, while one is kept as standby.

\subsection{Assumptions}

The assumptions used in developing the probabilistic model are:

1. There is no simultaneous failure (Khanduja et al. [28]).

2. At any given time, the system is either in full working state or in the failed state (Gupta et al. [35]).

3. Standby subsystems are of the same nature and capacity as that of active systems.

4. Service includes repair and/or replacement.

5. Failure/repair rates are constant over time and statistically independent (Kumar et al. [38]).

6. Sufficient repair facilities are available (Srinath [19]).

7. A repaired system is as good as new, performance wise, for a specified duration (Gupta et al. [36]).

8. System failure/repair follows the exponential distribution.

\section{Availability Simulation Modelling}

The availability simulation model has been developed for making the performance evaluation of SWAS using Markov concept. Markov modelling is based on the assumption that a system and its components can be in different states. A component, at lowest level, can be either up or down, while a system can be in any possible state identified depending on the components of which it is made up and the state they are in. A Markov model is a so-called state-space model and describes the transitions of one state to another. Wolstenholme [18] states that the transition probabilities only depend on the present state of the system. The model should include all components, the states they can be in and the frequency at which they change state. The flow of states for the system under consideration has been described in a transition diagram, which is based upon concepts given by Kumar et al. [39], as shown in fig. 3, which is logical representation of all possible state's probabilities encountered during the failure analysis of SWAS. According to O'Conner [23], a component has a failure frequency $\phi$ with which it changes from its up state to its down state and a repair frequency $\lambda$ with which it changes from its down state to its upstate. The failure and repair rates of the different subsystems are used as standard input information to the model. Formulation is carried out using the joint probability functions based on the transition diagram. These probabilities are mutually exclusive and provide the scope to implement Markovian approach for availability analysis of power generation process. 


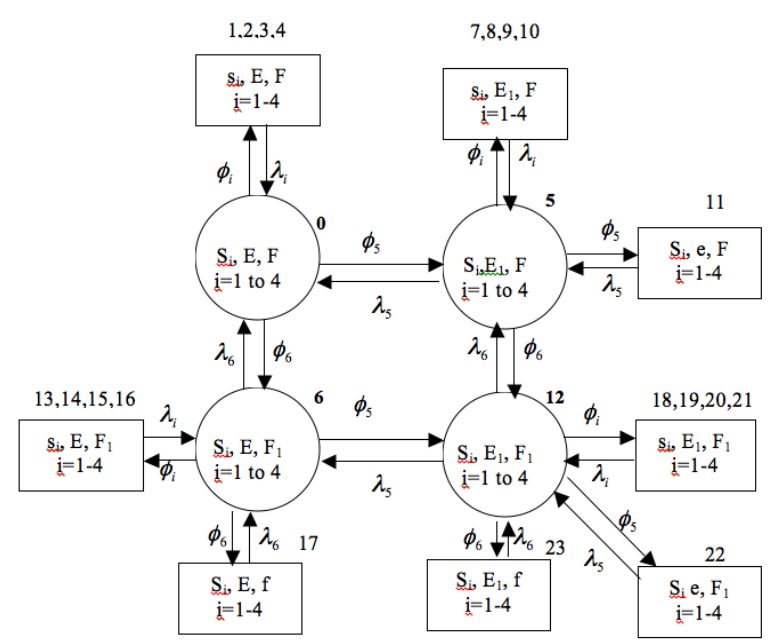

Fig 3. Transition Diagram of Steam and water analysis system (SWAS)

Markov model is defined by a set of probabilities $P_{i j}$, where $P_{i j}$ is the probability of transition from any state i to any state j. For example, the equipment transits from operable state i to failed state $\mathrm{j}$ with probability $P_{i j}$. One of the most important features of the Markov process is that the transition probability $P_{i j}$; depends only on states i and j and is completely independent of all past states except the last one, state i.

Let the probability of $\mathrm{n}$ occurrences in time $\mathrm{t}$ be denoted by $P_{n}(t)$, i.e.,

Probability $(\mathrm{X}=\mathrm{n}, \mathrm{t})=P_{n}(t)(\mathrm{n}=0,1,2 \ldots)$.

Then, $P_{0}(t)$ represent the probability of zero occurrences in time t. The probability of zero occurrences in time $(t+\Delta t)$ is given by equation 1; i.e.

$P_{0}(t+\Delta t)=(1-\lambda t) \cdot P_{0}(t)$

Similarly

$$
P_{1}(t+\Delta t)=(\phi \cdot \Delta t) \cdot P_{0}(t)+(1-\lambda \cdot \Delta t) \cdot P_{1}(t)
$$

The Eq. 2, as stated by Srinath [19], shows the probability of one occurrence in time $(\mathrm{t}+\Delta \mathrm{t})$ and is composed of two parts, namely, (a) probability of zero occurrences in time $t$ multiplied by the probability of one occurrence in the interval $\Delta \mathrm{t}$ and (b) the probability of one occurrence in time $t$ multiplied by the probability of no occurrences in the interval $\Delta \mathrm{t}$. Then simplifying and putting $\Delta t \rightarrow 0$, one gets

$$
\left(\frac{d}{d t}+\phi\right) P_{1}(t)=\lambda . P_{0}(t)
$$

Using the concept used in Eq. 3 and various probability considerations, the following differential equations associated with the transition diagram of SWAS are formed, as described by Kumar et al. [37].

$$
P^{\prime}{ }_{0}(t)+\sum_{i=1}^{i=6} \phi_{i} P_{0}(t)=\sum_{j=1}^{j=6} \lambda_{j} P_{j}(t)
$$

For $\mathrm{i}=5 ; \mathrm{m}=5$

$$
P_{5}^{\prime}(t)+\sum_{r=1}^{r=6}\left(\phi_{r}+\lambda_{m}\right) P_{i}(t)=\sum_{j=1}^{j=6} \lambda_{j} P_{j+6}(t)+\phi_{i} P_{i-5}(t)
$$

For $\mathrm{i}=6 ; \mathrm{m}=6$

$$
\begin{aligned}
& P_{6}^{\prime}(t)+\sum_{r=1}^{r=6}\left(\phi_{r}+\lambda_{m}\right) P_{i}(t)=\sum_{j=1}^{j=4} \lambda_{j} P_{j+12}(t)+ \\
& +\phi_{i} P_{i-6}(t)+\lambda_{i} P_{i+11}(t)+\lambda_{i-1} P_{i+6}(t)
\end{aligned}
$$

For $\mathrm{i}=12 ; \mathrm{m}=5,6$

$$
\begin{aligned}
& \left.P_{12}^{\prime}(t)+\sum_{r=1}^{r=6}\left(\phi_{r}+\lambda_{m}\right)\right) P_{i}(t)= \\
& =\sum_{j=1}^{j=6} \lambda_{j} P_{j+17}(t)+\phi_{i-6} P_{i-7}(t)+\phi_{i-7} P_{i-6}(t)
\end{aligned}
$$

$P_{i}^{\prime}(t)+\lambda_{i} P_{i}(t)=\phi_{i} P_{k}(t)$, For $\mathrm{i}=1-4, \mathrm{k}=0$

$P_{i}^{\prime}(t)+\lambda_{i-6} P_{i}(t)=\phi_{i-6} P_{k}(t)$ For i=7-11, k=5

$P_{i}^{\prime}(t)+\lambda_{i-12} P_{i}(t)=\phi_{i-12} P_{k}(t)$ For i=13-17, k=6

$P_{i}^{\prime}(t)+\lambda_{i-17} P_{i}(t)=\phi_{i-17} P_{k}(t)$ For i=18-23, k=12 (11)

With the initial condition $\mathrm{P}_{0}(0)=1$ and zero otherwise.

Since any thermal plant is a process industry where raw material is processed through various subsystems continuously till the final product is obtained. Thus, as stated by Arora and Kumar [21], putting derivative of all probability equal to zero yields the long run availability of the thermal plant i.e. by putting $P_{i}^{\prime}(t)=0$ at $t \rightarrow \infty$ into differential Eq. (4 to11), and solving these equations recursively, yields the following values of all state probabilities in terms of full working state probability i.e. $\mathrm{P}_{0}$.

$$
\begin{aligned}
& P_{1}=\frac{\phi_{1}}{\lambda_{1}} P_{0}, \quad P_{2}=\frac{\phi_{2}}{\lambda_{2}} P_{0}, P_{3}=\frac{\phi_{3}}{\lambda_{3}} P_{0}, P_{4}=\frac{\phi_{4}}{\lambda_{4}} P_{0}, \\
& P_{6}=C_{9} P_{0}, P_{5}=C_{10} P_{0}, P_{7}=\frac{\phi_{1}}{\lambda_{1}} P_{5}, P_{8}=\frac{\phi_{2}}{\lambda_{2}} P_{5}, \\
& P_{9}=\frac{\phi_{3}}{\lambda_{3}} P_{5}, P_{10}=\frac{\phi_{4}}{\lambda_{4}} P_{5}, P_{11}=\frac{\phi_{5}}{\lambda_{5}} P_{5}, P_{12}=C_{11} P_{0}, \\
& P_{13}=\frac{\phi_{1}}{\lambda_{1}} P_{6}, P_{14}=\frac{\phi_{2}}{\lambda_{2}} P_{6}, P_{15}=\frac{\phi_{3}}{\lambda_{3}} P_{6}, P_{16}=\frac{\phi_{4}}{\lambda_{4}} P_{6},
\end{aligned}
$$




$$
\begin{aligned}
& P_{17}=\frac{\phi_{6}}{\lambda_{6}} P_{6}, P_{18}=\frac{\phi_{1}}{\lambda_{1}} P_{12}, P_{19}=\frac{\phi_{2}}{\lambda_{2}} P_{12} \\
& P_{20}=\frac{\phi_{3}}{\lambda_{3}} P_{12}, P_{21}=\frac{\phi_{4}}{\lambda_{4}} P_{12}, P_{22}=\frac{\phi_{5}}{\lambda_{5}} P_{12}, \\
& P_{23}=\frac{\phi_{6}}{\lambda_{6}} P_{12}
\end{aligned}
$$

\subsection{Normalizing Condition}

The probability of full working capacity, namely, $\mathrm{P}_{0}$ determined by using normalizing condition [32]: (i.e sum of the probabilities of all working states and failed states is equal to 1 )

i.e. $\sum_{i=0}^{23} P_{i}=1$, therefore putting the values of $P_{0}$ to $P_{23}$ and solving, one gets:

$$
\begin{aligned}
& P_{0}=1 /\left[\left(1+C_{9}+C_{10}+C_{11}\right)\right. \\
& \left(1+\frac{\phi_{1}}{\lambda_{1}}+\frac{\phi_{2}}{\lambda_{2}}+\frac{\phi_{3}}{\lambda_{3}}+\frac{\phi_{4}}{\lambda_{4}}\right)+ \\
& \left.+\frac{\phi_{5}}{\lambda_{5}}\left(C_{10}+C_{11}\right)+\frac{\phi_{6}}{\lambda_{6}}\left(C_{9}+C_{11}\right)\right]
\end{aligned}
$$

Where,

$$
\begin{aligned}
& C_{1}=\phi_{5}+\phi_{6}, \\
& C_{2}=\phi_{6}+\lambda_{5}, \\
& C_{3}=\phi_{5}+\lambda_{6}, \\
& C_{4}=\lambda_{5}+\lambda_{6}, \\
& C_{5}=\frac{\lambda_{5} \phi_{6}}{C_{3} C_{4}-\phi_{5} \lambda_{5}}, \\
& C_{6}=\frac{\phi_{6} C_{4}}{C_{3} C_{4}-\phi_{5} \lambda_{5}}, \\
& C_{7}=\frac{C_{4} \phi_{5}}{C_{2} C_{4}-\phi_{6} \lambda_{6}}, \\
& C_{8}=\frac{\phi_{5} \lambda_{6}}{C_{2} C_{4}-\phi_{6} \lambda_{6}}, \\
& C_{9}=\frac{C_{6}+C_{5} C_{7}}{1-C_{5} C_{8}}, \\
& C_{10}=C_{7}+C_{8} C_{9}, \\
& C_{11}=\frac{C_{10} \phi_{6}+C_{9} \phi_{5}}{C_{4}}
\end{aligned}
$$

\subsection{Steady State availability}

Now, the steady state availability of SWAS may be obtained as summation of all working states probabilities [33] as:

Av. =Summation of all working states

$$
\begin{aligned}
& \text { i.e. } \mathrm{A}_{\mathrm{v}}=\mathrm{P}_{0}+\mathrm{P}_{5}+\mathrm{P}_{6}+\mathrm{P}_{12} \\
& \text { or } A_{V}=P_{0}\left(1+C_{9}+C_{10}+C_{11}\right)
\end{aligned}
$$

\section{Performance Evaluation For Decision Making}

The performance of steam and water analysis system of thermal power plant is mainly affected by the failure and repair rates of each subsystem [34]. The availability simulation model is used to evaluate the performance of SWAS for known input values of failure and repair rates of its components. From maintenance history sheet of SWAS and through the discussions with the plant personnel, appropriate failure and repair rates of all subsystems are taken and availability decision matrices (availability values) are prepared accordingly by putting these failure and repair rates values in Eq.13, the availability simulation model $\left(\mathrm{A}_{\mathrm{v}}\right.$. $)$. This model forms the foundation for all other performance improvement activities (e.g. solution design and development, implementation and analysis). These unit parameters ensure the high availability/performance of the SWAS. This model includes all possible states of nature, i.e. failure events $\left(\phi_{i}\right)$ and the identification of all the courses of action, i.e., repair priorities $\left(\lambda_{i}\right)$. Tab. 1 to 6 represents the availability decision matrices for various subsystems of the SWAS. These matrices simply reveals the various availability levels for different combinations of failure and repair rates/priorities, which further helps in decision making of maintenance priorities for each subsystem i.e. which subsystem is most critical from maintenance point of view, for which immediate action is required and which one is least critical. On the basis of analysis made, the best possible combinations $(\phi, \lambda)$ may be selected. These availability values in availability decision matrices further help in decision making regarding the subsystem which ensures the maximum availability, as shown in tab. 7. The decision making regarding the optimum vales of failure/repair rates of each subsystem of concerned system can easily be taken from tab. 7 .

\section{Results and Discussion}

The performance of each subsystem is analysed using the developed model. On the basis of availability values as given in tab. 1 to 6 , the following observations are made, which reveals the effect of failure and repair rates of various subsystems on the availability of SWAS.

1. Tab. 1 reveals the effect of failure and repair rates of turbine subsystem on the availability of SWAS. It is observed that for some known values of failure / repair rates of other five subsystems, as failure rate of turbine increases from 0.002 (twice in $1000 \mathrm{hrs}$ ) to 0.01 (once in $100 \mathrm{hrs}$ ), the system availability decreases by about $6 \%$. Similarly as repair rate of turbine increases from 0.04 (4 
times in $100 \mathrm{hrs}$ ) to 0.1 (once in $10 \mathrm{hrs}$ ), the system availability increases by about $1 \%$.

2. Tab. 2 reveals the effect of failure and repair rates of boiler subsystem on the availability of SWAS. It is observed that for some known values of failure / repair rates of other five subsystems, as failure rate of boiler increases from 0.0006 (6 times in $10000 \mathrm{hrs)}$ to 0.001 (once in $1000 \mathrm{hrs}$ ), the system availability decreases by about $1 \%$. Similarly as repair rate of boiler increases from 0.02 (once in $50 \mathrm{hrs}$ ) to 0.1 (once in $10 \mathrm{hrs}$ ), the system availability increases by about $1 \%$.

3. Tab. 3 reveals the effect of failure and repair rates of condenser subsystem on the availability of SWAS. It is observed that for some known values of failure / repair rates of other five subsystems, as failure rate of condenser increases from 0.005 ( 5 times in $1000 \mathrm{hrs}$ ) to 0.01 (once in $100 \mathrm{hrs}$ ), the system availability decreases by about $2 \%$. Similarly as repair rate of condenser increases from 0.1 (once in $10 \mathrm{hrs)}$ ) to 0.5 (twice in 10 hrs), the system availability increases by about $1.25 \%$.

4. Tab. 4 reveals the effect of failure and repair rates of heaters subsystem on the availability of SWAS. It is observed that for some known values of failure / repair rates of other five subsystems, as failure rate of heaters increases from 0.005 ( 5 times in $1000 \mathrm{hrs}$ ) to 0.01 (once in $100 \mathrm{hrs}$ ), the system availability decreases by about $3.5 \%$. Similarly as repair rate of heaters increases from 0.1 (once in $10 \mathrm{hrs}$ ) to 0.4 ( 4 times in $10 \mathrm{hrs}$ ), the system availability increases by about $3 \%$.

5. Tab. 5 reveals the effect of failure and repair rates of condensation extraction pump subsystem on the availability of SWAS. It is observed that for some known values of failure / repair rates of other five subsystems, as failure rate of condensation extraction pump increases from 0.01 (once in $100 \mathrm{hrs)} \mathrm{to} 0.05$ (5 times in $100 \mathrm{hrs}$ ), the system availability decreases by about $6 \%$. Similarly as repair rate of condensation extraction pump increases from 0.125 (once in $8 \mathrm{hrs}$ ) to 0.425 (once in $2.3 \mathrm{hrs}$ ), the system availability increases slightly.

6. Tab. 6 reveals the effect of failure and repair rates of feed pump subsystem on the availability of SWAS. It is observed that for some known values of failure / repair rates of other five subsystems, as failure rate of feed pump increases from 0.02 (twice in $100 \mathrm{hrs)} \mathrm{to} 0.1$ (once in $10 \mathrm{hrs}$ ), the system availability decreases by about $21 \%$. Similarly as repair rate of feed pump increases from 0.1 (once in $10 \mathrm{hrs}$ ) to 0.5 (twice in 10 hrs), the system availability increases by about $6 \%$.

7. Tab. 7 helps in decision making regarding the subsystem with maximum availability. It is observed that feed pump subsystem is having maximum availability $(89.5 \%)$, which is followed by turbine, having availability $86 \%$. The decision regarding the optimum values of failure and repair rates for maximum availability level for each subsystem can easily be taken from table 7. It also describes the optimum vales of failure/repair rates of each subsystem of concerned system.

8. Tab. 1 to 6 depicts the effect of failure rates of various subsystems on system's availability, as indicated in tab. 8 . It is evident from table 8 that the feed pump is most critical subsystem as far as maintenance aspect is concerned, as the effect of its failure rates on the system availability is much higher $(21 \%)$ than other five subsystems. Further Boiler is the least critical subsystem, as the effect of its failure rates on the system availability is lowest amongst all six subsystems.

Table 1. Availability decision matrix of Turbine subsystem of SWAS

\begin{tabular}{|c|c|c|c|c|c|c|}
\hline \multirow{2}{*}{\multicolumn{7}{|c|}{ Constant xalues }} \\
\hline & & & & & 0.1 & Constant xalues. \\
\hline 0.002 & 0.8500 & 0.8546 & 0.8572 & 0.8589 & 0.8601 & \multirow{5}{*}{$\begin{array}{l}\phi_{2}=0.0008, \phi_{3}=0.0076 \\
\phi_{4}=0.0076, \phi_{5}=0.03, \phi_{6}=0.06 \\
\lambda_{2}=0.06, \lambda_{3}=0.3, \lambda_{4}=0.25 \\
\lambda_{5}=0.275, \lambda_{6}=0.3\end{array}$} \\
\hline 0.004 & 0.8337 & 0.8425 & 0.8476 & 0.8510 & 0.8533 & \\
\hline 0.006 & 0.8181 & 0.8309 & 0.8383 & 0.8432 & 0.8467 & \\
\hline 0.008 & 0.8030 & 0.8195 & 0.8292 & 0.8356 & 0.8402 & \\
\hline 0.01 & 0.7885 & 0.8082 & 0.8203 & 0.8281 & 0.8337 & \\
\hline
\end{tabular}

Table 2. Availability decision matrix of Boiler subsystem of SWAS

\begin{tabular}{|c|c|c|c|c|c|c|}
\hline & 0.02 & 0.04 & 0.06 & 0.08 & 0.1 & Constant values \\
\hline 0.0006 & 0.8330 & 0.8378 & 0.8394 & 0.8402 & 0.8407 & \multirow{5}{*}{$\begin{array}{l}\phi_{1}=0.006, \phi_{3}=0.0076 \\
\phi_{4}=0.0076, \phi_{5}=0.03, \phi_{6}=0.06 \\
\lambda_{1}=0.07, \lambda_{3}=0.3 \\
\lambda_{4}=0.25, \lambda_{5}=0.275, \lambda_{6}=0.3\end{array}$} \\
\hline 0.0007 & 0.8314 & 0.8370 & 0.8389 & 0.8398 & 0.8404 & \\
\hline 0.0008 & 0.8298 & 0.8362 & 0.8384 & 0.8394 & 0.8400 & \\
\hline 0.0009 & 0.8281 & 0.8354 & 0.8379 & 0.8390 & 0.8397 & \\
\hline 0.001 & 0.8267 & 0.8346 & 0.8373 & 0.8386 & 0.8394 & \\
\hline
\end{tabular}

Table 3. Availability decision matrix of Condenser subsystem of SWAS

\begin{tabular}{|c|c|c|c|c|c|c|}
\hline \multicolumn{7}{|c|}{$\begin{array}{l}\text { Availability (Av) } \rightarrow \\
\begin{array}{|c|c}0.4 & 0.5\end{array}\end{array}$} \\
\hline 0.005 & 0.8304 & 0.8384 & 0.8411 & 0.8425 & 0.8433 & $\phi=0.006, \phi=0.0008$ \\
\hline 0.0063 & 0.8263 & 0.8363 & 0.8397 & 0.8414 & 0.8425 & $\phi_{4}=0.0076, \phi_{5}=0.03, \phi_{6}=0.06$ \\
\hline 0.0076 & 0.8223 & 0.8343 & 0.8383 & 0.8404 & 0.8416 & $\lambda_{1}=0.07, \lambda_{2}=0.06$ \\
\hline 0.0089 & 0.8183 & 0.8322 & 0.8369 & 0.8394 & 0.8407 & \\
\hline 0.0102 & 0.8143 & 0.8301 & 0.8355 & 0.8383 & 0.8399 & \\
\hline
\end{tabular}

Table 4. Availability decision matrix of Heaters subsystem of SWAS

\begin{tabular}{|c|c|c|c|c|c|c|}
\hline & 01 & 0175 & $0250 \quad 2$ & Avallabi & Av) & Cont? t alne \\
\hline 0.005 & 0.8248 & 0.8396 & 0.8457 & 0.8490 & 0.8511 & \multirow{5}{*}{$\begin{array}{l}\phi_{1}=0.006, \phi_{2}=0.0008 \\
\phi_{3}=0.0076, \phi_{5}=0.03, \phi_{6}=0.06 \\
\lambda_{1}=0.07, \lambda_{2}=0.06 \\
\lambda_{3}=0.3, \lambda_{5}=.275, \lambda_{6}=0.3\end{array}$} \\
\hline 0.0063 & 0.8160 & 0.8344 & 0.8420 & 0.8461 & 0.8488 & \\
\hline 0.0076 & 0.8075 & 0.8293 & 0.8383 & 0.8433 & 0.8464 & \\
\hline 0.0089 & 0.7991 & 0.8242 & 0.8347 & 0.8403 & 0.8441 & \\
\hline 0.0102 & 0.7909 & 0.8192 & 0.8311 & 0.8375 & 0.8418 & \\
\hline
\end{tabular}

Table 5. Availability decision matrix of Condensate extraction pump subsystem of SWAS

\begin{tabular}{|c|c|c|c|c|c|c|}
\hline$\lambda_{5}$ & 0.125 & 0.2 & 0.275 & 0.350 & 0.425 & Constant values \\
\hline 0.01 & 0.8403 & 0.8405 & 0.8408 & 0.8409 & 0.8417 & \multirow{5}{*}{$\begin{array}{l}\phi_{1}=0.006, \phi_{2}=0.0008 \\
\phi_{3}=0.0076, \phi_{4}=.0076, \phi_{6}=0.06 \\
\lambda_{1}=0.07, \lambda_{2}=0.06 \\
\lambda_{3}=0.3, \lambda_{4}=0.25, \lambda_{6}=0.3\end{array}$} \\
\hline 0.02 & 0.8342 & 0.8392 & 0.8401 & 0.8402 & 0.8402 & \\
\hline 0.03 & 0.8219 & 0.8349 & 0.8383 & 0.8395 & 0.8399 & \\
\hline 0.04 & 0.8051 & 0.8282 & 0.8351 & 0.8377 & 0.8389 & \\
\hline 0.05 & 0.7851 & 0.8194 & 0.8305 & 0.8351 & 0.8373 & \\
\hline
\end{tabular}


Table 6. Availability decision matrix of Feed pump subsystem of SWAS

\begin{tabular}{|c|c|c|c|c|c|c|}
\hline \multicolumn{7}{|c|}{ Availability $(\mathrm{Av}) \rightarrow$} \\
\hline${\hat{\phi_{6}}}_{6}^{\lambda_{0}}$ & 0.1 & 0.2 & 0.3 & 0.4 & 0.5 & Constant xalues \\
\hline 0.02 & 0.8375 & 0.8728 & 0.8853 & 0.8916 & 0.8955 & $\phi=0.006, \phi_{2}=0.0008$ \\
\hline 0.04 & 0.7742 & 0.8380 & 0.8613 & 0.8374 & 0.8808 & $\phi_{3}=0.0076, \phi_{4}=0.0076, \phi_{5}=0.03$ \\
\hline 0.06 & 0.7186 & 0.8053 & 0.8383 & 0.8557 & 0.8664 & $\begin{array}{l}M_{1}=0.07, \lambda_{2}=0.06 \\
\lambda_{1}=0.3 \lambda=0.25 \lambda=0275\end{array}$ \\
\hline 0.08 & 0.6695 & 0.7746 & 0.8163 & 0.8386 & 0.8524 & \\
\hline 0.1 & 0.6260 & 0.7459 & 0.7951 & 0.8219 & 0.8387 & \\
\hline
\end{tabular}

Table 7. Optimum values of failure and repair rates of subsystems of SWAS

\begin{tabular}{c|c|c|c|c}
\hline S.No. & Subsystem & Failure rates $\left(\phi_{i}\right)$ & $\begin{array}{c}\text { Repair } \\
\text { rates }\left(\lambda_{i}\right)\end{array}$ & $\begin{array}{c}\text { Maximum } \\
\text { availability level }\end{array}$ \\
\hline 1. & Turbine & $\phi_{1}=0.002$ & $\lambda_{1}=0.1$ & $86 \%$ \\
2. & Boiler & $\phi_{2}=0.0006$ & $\lambda_{2}=0.1$ & $84 \%$ \\
3. & Condenser & $\phi_{3}=0.005$ & $\lambda_{3}=0.5$ & $84 \%$ \\
4. & Heaters & $\phi_{4}=0.005$ & $\lambda_{4}=0.4$ & $85 \%$ \\
5. & Condensate & $\phi_{5}=0.01$ & $\lambda_{5}=0.425$ & $84 \%$ \\
& Extraction pump & & & \\
6. & Feed pump & $\phi_{6}=0.02$ & $\lambda_{5}=0.5$ & $89.5 \%$ \\
& & & & \\
\hline
\end{tabular}

Table 8: List of subsystems of SWAS in order of their maintenance priority

\begin{tabular}{c|c|c}
$\begin{array}{c}\text { Maintenance priority } \\
\text { No. }\end{array}$ & Subsystem & $\begin{array}{c}\text { Effect of failure rate }\left(\phi_{i}\right) \text { on } \\
\text { availability }\end{array}$ \\
\hline 1. & Feed pump & $-21 \%$ \\
2. & Turbine/ Condensate & $-6.0 \%$ \\
3. & Extraction pump & \\
4. & Heaters & $-3.5 \%$ \\
5. & Condenser & $-2.0 \%$ \\
\hline
\end{tabular}

\section{Conclusion}

It can be concluded from tables 1-6, that as failure rate increases, the availability goes on decreasing and as repair rate increases, the availability goes on increasing. The Eq. 13 depicts the availability simulation model, which helps in performance evaluation for decision making regarding maintenance for SWAS of thermal plant. The system availability has been excellent, mainly because of the low failure rate, supported by the state of the art repair facilities. It can thus be concluded that this model is effectively used for evaluation of performance of various sub-systems of SWAS, which further helps in decision making. It is also concluded that feed pump is most critical and boiler is the least critical subsystem as far as maintenance aspect is concerned. It is also concluded that feed pump subsystem is having maximum availability. The optimum values of failure and repair rates for maximum availability level for each subsystem are available. Such results are found highly beneficial to the plant management for the availability analysis and maintenance decision making of steam and water analysis system of a thermal plant.

\section{Acknowledgement}

The author is grateful to Sh. Sushil Bansal Ji, SE, Panipat Thermal Power Plant (No.5), Panipat, for providing every possible help during the work.

\section{References}

1. A.Birolini, Quality and reliability of technical systems. Berlin, Springer (1994).

2. A.Hoyland and M.Rausand, System Reliability Theory, New York, Wiley (1994).

3. A.K. Somani, J.A. Ritcey and S.H. Au Computationally Efficient Phased Mission Reliability Analysis for Systems with Variable Configuration. IEEE Transactions on Reliability, 41(4), 504-511 (1992).

4. A.K. Somani, T. Sharma and P.H. Nguyen, Reliability Computation of Systems with Latent-Failures and Monitoring. In: Proc. of 1994 Annual Reliability and Maintainability Symposium, 195-200, (1994).

5. A.M. Johnson Jr. and M. Malek, Survey of Software Tools for Evaluating Reliability, Availability and Serviceability, ACM Computing Surveys, 20(4), 227-269 (1988).

6. B.S. Dhillon, Reliability Engineering in Systems Design and Operation.New York, Van Nostrand-Reinhold (1983).

7. B.V. Gnedenko and I.A. Ushakov, Probabilistic Reliability Engineering. New York: Wiley (1995).

8. C. Beounes et al., SURF-2: A Program for Dependability Evaluation of Complex Hardware and Software Systems. In: 23rd Int. Symp. on Fault-Tolerant Computing: Toulouse, France, 668673 (1993).

9. C.E. Ebling, An Introduction to Reliability and Maintainability Engineering. New Delhi: TMH Publishing Company Limited (1997).
10. E. Balaguruswamy, Reliability Engineering. New Delhi, Tata McGraw Hill (1984).

11. G. Ciardo, J. Muppala and K. Trivedi, SPNP: Stochastic Petri Net Package. In: Proc. 3rd Int. Workshop on Petri Nets and Performance Models, Kyoto, Japan, 142-151(1989).

12. G.Krishnamurthi, A. Gupta and A.K. Somani, The HIMAP Modelling Environment. In: Proceedings of the 9th International Conference on Parallel and Distributed Computing Systems: Dijon, France, 254-259 (1996).

13. Igor. Ushakov, Reliability: Past, Present, Future, in Recent Advances in Reliability Theory, 3-21, Stat. Ind. Technol., Birkha user Boston, Boston, MA (2000).

14. J. Barabady, and U. Kumar, Reliability Analysis of Mining Equipment: A Case Study of a Crushing, Reliability Engineering and System Safety, 93, 647-653 (2008)

15. J.A. Van, A Feasibility Study By Means of the Development of a Simulation Model for the Resin Plant of the Lexan ${ }^{\circledR}$ Production Train of GE Plastics. Master of Science thesis at the faculty of Technology, Policy and Management of Delft Technical University (2003).

16. J.M. Koren and J.Gaertner, CAFTA: A Fault Tree Analysis Tool Designed for PSA. In: Proc. of Probabilistic Safety Assessment and Risk Management: PSA, Zurich, Switzerland, 2, 588-592 (1987).

17. K.C. Kurien, Reliability and Availability Analysis of Repairable System Using Discrete Event Simulation. Ph. D. thesis, IIT, New Delhi (1988). 
18. L.C. Wolstenholme, Reliability Modelling-A Statistical Approach, Chapman \& Hall, CRC (1999).

19. L.S. Srinath, Reliability Engineering. 3rd edition, New Delhi, India. East-West Press Pvt. Ltd (1994).

20. M. Malhotra and K.S. Trivedi, Power-Hierarchy of DependabilityModel Types. IEEE Transactions on Reliability, 43(3):493-502 (1994).

21. N. Arora and D. Kumar, Availability Analysis of Steam and Power Generation System in Thermal Power Plant, Micro electron Reliability, 37(5); 95-99 (1997).

22. P.C. Sharma, Power Plant Engineering, N. Delhi, India, S.K.Kataria and sons (2006).

23. P.D.T. O'Conner, Practical Reliability Engineering, Chichester, John Wiley \& Sons Ltd (1995).

24. R. Butler, The SURE Reliability Analysis Program, AIAA Guidance, Navigation and Control Conference: Williamsburg, VA (1986).

25. R.A. Sahner and K.S. Trivedi, Reliability Modelling Using SHARPE. IEEE Trans Reliability, R 36(2):186-193 (1987).

26. R.G. Lamb, Availability Engineering \& Management for Manufacturing Plant Performance. New Jersey, Prentice-Hall (1995).

27. R. Khan and A.B.M. Kabir, Availability Simulation of an Ammonia Plant. Elsevier Science Ltd. (1995).

28. R. Khanduja, P.C. Tewari and D. Kumar, Availability Analysis of Bleaching System of Paper Plant. Journal of Industrial Engineering, Udyog Pragati, N.I.T.I.E. Mumbai (India), 32(1), 24-29 (2008).

29. R.W. Butler, An Abstract Language for Specifying Markov Reliability Models. IEEE Trans on Reliability, R (35), 595-602 (1986).

30. S. Bernson, E.de Souza e Silva and R. Muntz, A Methodology for the Specification of Markov Models. In: Stewart W, editor. Numerical Solution to Markov Chains, Boston, MA: Kluwer: 1137 (1991)

31. S. Gupta and P.C. Tewari, Simulation model for coal crushing system of a typical thermal power plant, International Journal of Engineering and Technology (IJET), Singapore (Accepted for publication on 23.0.2009).

32. S. Gupta and P.C. Tewari, Simulation model for stochastic analysis and performance evaluation of condensate system of a thermal power plant, Bangladesh Journal of Scientific and Industrial Research (BJSIR). (Accepted for publication on 06.05.2009).

33. S. Gupta, P.C. Tewari and A. K. Sharma, "Availability simulation model and performance analysis of coal handling unit of a typical thermal plant", South African Journal of Industrial Engineering, 20 (1), 159-71 (2009)

34. S. Gupta, P.C. Tewari and A. K. Sharma, "Development of simulation model for performance evaluation of feed water system in a typical thermal power plant" Journal of Industrial Engineering International (JIEI). (Accepted for publication on 01.03.2009)

35. S. Gupta, P.C. Tewari and A.K. Sharma, Performance Modelling and Decision Support System of Feed Water Unit of a Thermal Power Plant, South African Journal of Industrial Engineering, 19 (2), 125-134 (2008).

36. S. Gupta, P.C. Tewari and A.K. Sharma, Reliability and Availability Analysis of Ash Handling System of a Steam Thermal Power Plant, South African Journal of Industrial Engineering, 20 (1), 147-158 (2009).

37. S. Kumar, P.C. Tewari and R. Sharma, Simulated Availability of $\mathrm{CO} 2$ Cooling System in a Fertilizer Plant. Industrial Engineering Journal (Indian Institution of Industrial Engineering, Mumbai), 36(10), 19-23 (2007).

38. S. Kumar, P.C. Tewari and S.Kumar, Performance Modelling and Simulated Availability of Shell Gasification and Carbon Recovery System of Urea Plant. Proceedings of the 16th IASTED International Conference held at Spain, 409-413 (2007).

39. S. Kumar, D. Kumar and N.P. Mehta, Maintenance Management for Ammonia Synthesis System in a Urea Fertilizer Plant. International Journal of Management and System (IJOMAS), 15(3), 211-214 (1999).

40. T.Avel and U. Jensen, Stochastic models of reliability, Berlin, Springer, (1999).

41. T.J. Lim and H.K. Chang, Analysis of System Reliability with Dependent Repair Models. IEEE Trans Reliab, 49(2), 153-62 (2000).

42. W.H. Sanders and W.D. Obal II, Dependability Evaluation Using UltraSAN. In: Proc. of the Twenty-Third International Symposium on Fault- Tolerant Computing, 674-679 (1993).

43. W.R. Blischke and D.N.P. Murthy, Case Studies in Reliability and Maintenance. USA, Wiley (2003). 